\title{
Plastic Load Evaluation for a Fixed Tube Sheet Heat Exchanger subject to proportional Loading
}

\author{
Khosrow Behseta ${ }^{1}$, Donald Mackenzie, Robert Hamilton \\ Department of Mechanical Engineering, \\ University of Strathclyde \\ Glasgow G1 1XJ \\ Scotland, U.K
}

The plastic load of pressurized components can be calculated based on both the twice elastic slope and tangent methods. Both methods are problematic since they rely on parameters that are localized and therefore have a strong dependency on the gradient of the stress-strain diagram in the plastic region. The criterion of curvature of plastic work is a suitable replacement for the above techniques. This method calculates total plastic work done on the structure and relates its change to the curvature of the load-plastic work plot. In this work the plastic load has been calculated for a fixed tube sheet exchanger according to curvature criteria using various hardening scenarios. Plastic loads calculated by other methods also have been reported. It has been indicated that tube sheet thickness calculated according to the classical ASME procedure can be significantly reduced when based on the curvature criteria.

\section{Introduction}

Heat exchanger tube sheets are a significant expense in power and process plant, where large numbers of heat exchangers may be used. The cost of a tube sheet is dependent on the basic thickness required to satisfy safety and functional considerations, not only in terms of material cost but also the added manufacturing costs associated with machining, drilling, welding and NDT. These costs rise greatly as tube sheet thickness increases and it is financially advantageous to minimise the required tube sheet thickness at the design stage.

Conventional tube sheet design is based on modified elastic plate bending theory, in which the perforated tube sheet is treated as a thin homogeneous plate with modified material properties used to simulate the structural effect of the perforations. In pressure vessel Design by Formula procedures, for example ASME VIII Div 1 and Div 2 [1, 2], design factors are applied to the solid plate model to account for exchanger type, tube pitch and other geometrical information. The conventional approach is safe and functionally effective but may lead to over-conservative designs in which the plate thickness is greater than that required to safely contain the pressurised fluids in the heat exchanger. This conservatism can be reduced by basing the design on a more detailed stress analysis of the component through application of Code Design by Analysis (DBA) procedures. Codes such as ASM E III [3], ASME VIII Div 2 and EN13445 [4] provide methodologies for design based on both elastic and inelastic analysis.

Fixed tube sheet exchangers are subject to a steady- state steady flow loading during their normal operation and criteria of scheduled start-up to full shut-down, they also are also subject to an emergency shut-down mode. This work is based on the steady-state steady-flow mode and possible fluctuations in operating pressure and operating temperature from steady-state operation are not considered in this work, such a notion is treated in a separate paper dealing with fatigue characteristics of the tube sheet which encompasses the effect of above variations.

\footnotetext{
${ }^{1}$ Corresponding Author e-mail: behsetaeq@yahoo.com
} 
It should be further noted that tubesheet and reactors are protected against excess fluctuations and large variations in pressure and temperature from normal operating mode, fluctuations in pressure or temperature occurs not from design conditions but from operating parameters. Tubesheet and reactors are protected by continuous monitoring of the flow parameters both on the shell and on the tube side, shutdown logic will be activated if pre-set parameters are exceed (data sheet in Ref [5]). This means the tube sheet will never experience non proportional loading, i.e., a rise in one parameter, for example pressure, in expense of the drop in the other one, for example temperature loads, beyond its protected range.

The elastic design procedures use a stress categorisation methodology to guard against failure due to gross plastic deformation and progressive plastic deformation or ratcheting. In practice, 3D Finite Element Analysis is employed to calculate the elastic stress field, with a stress linearization procedure employed to evaluate membrane and bending stresses for design assessment. This approach can yield a less conservative design than design by rule but does not lead to the most effective use of material possible. ASME VIII Div 2 A5.2.1.4 states "The structural evaluation procedures based on elastic stress analysis ... provide an approximation of the protection against plastic collapse. A more accurate estimate of the protection against plastic collapse of a component can be obtained using elastic-plastic stress analysis to develop limit and plastic collapse loads." The EN13445 direct route and ASME inelastic design rules provide procedures for design based on inelastic analysis.

EN13445 restricts the material model to be used to elastic-perfectly plastic. When applied in a small deformation analysis, the calculated plastic collapse load is the limit load of the structure. In a structure exhibiting geometric weakening, EN13445 specifies use of large deformation theory and the evaluated collapse load is treated as a lower bound on the limit load for design purposes. Taking a C2-Hydrogenation reactor as an example on a specific petrochemical plant, Behseta and Schindler [5] showed that the direct route led to a thinner tube sheet design than that required by design by rule procedures (ASME VIII Division 1 and EN 13445-3 Clause 13 and Annex J).

ASME III and ASME VIII Div 2 also provide procedures for design based on limit analysis; that is, an elasticperfectly plastic model and small deformation theory. In addition, these Codes also provide plastic analysis procedures for design based on an analysis incorporating material strain hardening and/or large deformation theory.

The potential advantage of design based on plastic analysis is that including material strain hardening may result in calculation of a plastic load higher than the limit load of the structure. However, in practice the evaluated plastic load is dependent on the criterion of plastic collapse used in the design assessment. The object of this paper is to investigate the effect of different strain hardening models on the evaluated plastic load and hence design pressure of the reactor tube sheet investigated in reference [5].

\section{Plastic Design Procedure}

The material model specified by the designer for ASME III plastic analysis may vary in complexity from simple bilinear hardening models to more complex curves defining the actual stress-strain curve. Small deformation theory or large deformation theory may be used, at the discretion of the designer. The ASME III plastic collapse load is determined by applying the twice elastic slope criterion, a graphical technique for establishing the plastic load from a load-deformation relationship obtained by plastic analysis. The load is plotted as the ordinate and the deformation parameter - deflection or strain - as the abscissa, as illustrated in Figure 1. The load-deformation curve is initially linear but becomes non-linear when the limit of proportionality is reached. The plastic collapse load is defined by plotting a straight collapse limit line from the origin with twice the slope of the initial elastic response: that is $\tan \varphi=2 \tan \theta$ in Figure 1 . The twice elastic slope load $\mathbf{P}_{\varphi}$, corresponding to the intersection point of the load-deformation curve and the collapse 
limit line, is taken as the plastic collapse load in DBA (subject to a maximum strain and triaxiality check).

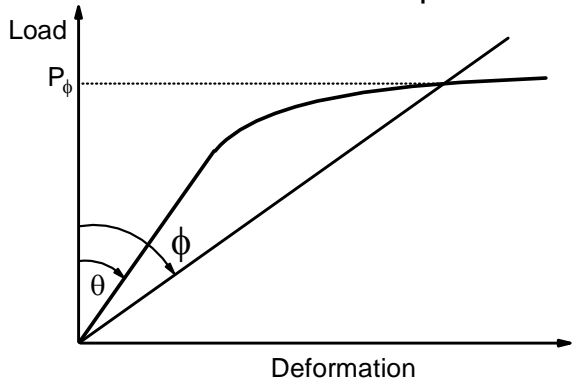

Figure 1. Twice elastic slope criterion

The twice elastic slope criterion load and deformation parameters are required to characterise the plastic behaviour of the vessel, especially the formation of collapse mechanisms. The choice of type and location of the parameter is at the discretion of the designer.

Prior to 2007, the ASME VIII Div 2 guidelines for plastic analysis were similar to those in ASME III. The 2007 ASME III Div 2 plastic analysis procedures are significantly different to previous versions; most notably, the von Mises yield criterion is specified as the design stress basis (as opposed to the Tresca criterion used in ASM E III), large deformation theory must be used and two Acceptance Criteria are specified in place of the twice elastic slope criterion. In addition, an optional true stress-strain curve that can be wholly derived from standard ASME material data is specified in Appendix 3.D. When using this model, the hardening behaviour is included up to the true ultimate stress and perfect plasticity behaviour assumed beyond this limit.

The two Acceptance Criteria are a Global criterion that requires demonstration that the design does not experience overall structural instability (plastic collapse) under the specified design load cases, indicated by convergence failure in the analysis, and Service criteria that limit the potential for unsatisfactory performance under the allowable loads evaluated according to the global criterion. In addition to designing against global plastic collapse, a local strain limit failure criterion is defined.

Several workers have proposed alternative plastic collapse criteria to those currently used in the ASME procedures. Two which will be considered in this investigation are the tangent intersection (TI) criterion and Plastic Work Curvature (PWC) criterion. The TI criterion is an alternative graphical construction method applied to the load deformation curve used in the TES criterion as shown in Figure 2 [11].

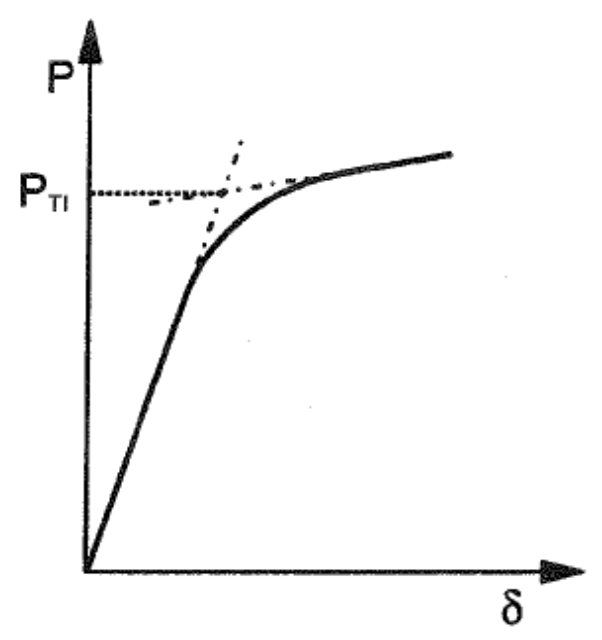

Figure 2. Tangent intersection criterion.

The PWC criterion is based on consideration of the plastic dissipation as load increases post-yield. This criterion was developed from an earlier plastic work criterion proposed by Muscat et al [6]. The concept of plastic work curvature (PWC) [9] identifies the plastic load by considering the curvature of the load- plastic 
work curve. The criterion is illustrated in Figure 3. shows a graph of load versus plastic work and a graph of curvature versus Plastic work plotted on the same diagram.

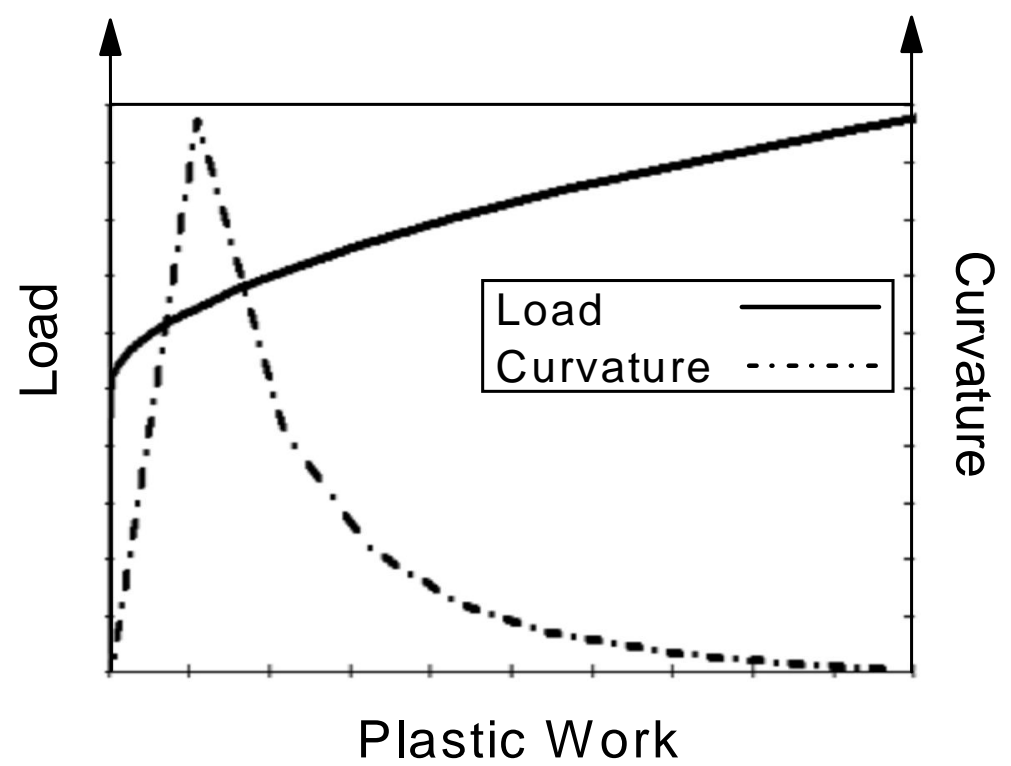

Figure 3, Graphs illustrating the concept of plastic work curvature

The curvature identifies the rate of change of plastic deformation. In the initial of elastic region, plastic work is zero, in upper stages of the elastic region, small plasticization occurs with very small curvature. Around yield the curvature starts to increase rapidly until it reaches its maximum value. A further increase in load reduces the curvature due to the post yielding behaviour and stress redistribution. The load corresponding to the peak curvature is the plastic load. Domination of gross - plastic deformation occurs at a loading corresponding to about $10 \%$ of the maximum curvature. In other words, curvature of plastic work criteria is quite unique as the procedure depends solely on the total plastic work done on the structure. In this criterion, load, plastic work and curvature of plastic work are simultaneously coupled and therefore the load causing peak curvature can be identified. The peak curvature indicates the start of gross-plastic deformation.

\section{Tubesheet Specification and Finite Element Model}

The reactor tubesheet considered is the largest and heaviest heat exchanger in a plant, a chemical reactor with 3200 tubes. Dimensions, properties, and basic material information, are given in reference [5] and summarized below:

Design fluid temperature on tube side $=-4 / 190^{\circ} \mathrm{C}$ Design fluid temperature on shell side $=-4 / 145^{\circ} \mathrm{C}$ Design pressure shell side $=1 \mathrm{MPa}$

Design pressure tube side $=4 \mathrm{MPa}$

Shell side mean wall temperature $=50^{\circ} \mathrm{C}$

Tube sheet mean wall temperature $=100^{\circ} \mathrm{C}$

A sketch of the area of interest local to the tube sheet/ channel connection is given in Figure 4 . The dimensions and uncorroded thickness after manufacture shown on Figure 4 were calculated using the classical ASM E [1],[2] design by rule procedures. 


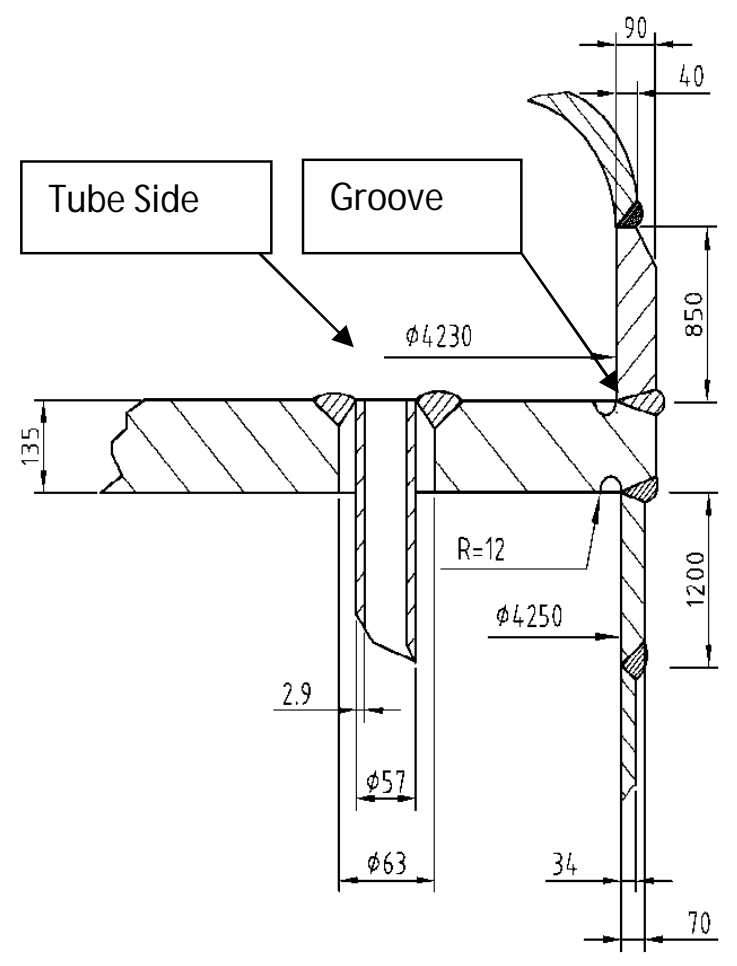

Figure 4. Tube sheet configuration and basic dimensions.

The material physical properties and material stress data were taken from ASME [15] and are given in Table 1. Values are reported at the calculation temperature. $S_{m}$ is the allowable stress based on Table $5 A$ of Ref [15].

Table (1) M aterial Properties Data at Calculated Temperature ${ }^{a}$

\begin{tabular}{|l|l|l|l|l|l|l|l|}
\hline Material & $\begin{array}{l}\text { Elasticity } \\
\text { Modulus } \\
\mathrm{E}(\mathrm{MPa})\end{array}$ & $\begin{array}{l}\mathrm{R}_{\mathrm{m}} / \mathrm{t}_{\text {calc. }} \\
(\mathrm{MPa})\end{array}$ & $\begin{array}{l}\text { Cold Yield } \\
\mathrm{Rp}, 0.2 / \\
20{ }^{\circ} \mathrm{C}\end{array}$ & $\begin{array}{l}\text { Hot Yield } \\
\mathrm{Rp}, 0.2 / \\
\text { tcalc. } \\
(\mathrm{MPa})\end{array}$ & $\mathrm{S}_{\mathrm{m}}$ & $1.5 \mathrm{~S}_{\mathrm{m}}$ & $\mathrm{t}_{\text {cal }}\left({ }^{\circ} \mathrm{C}\right)$ \\
\hline $\begin{array}{l}\text { Upper Shell } \\
\text { SA 537 Cl2 }\end{array}$ & 193053 & 542.41 & 380 & 317.2 & 229.6 & 344.4 & 190 \\
$\begin{array}{l}\text { Lower Shell } \\
\text { SA 516 Gr 70 }\end{array}$ & 195337 & 482.3 & 260 & 232 & 154.7 & 232 & 145 \\
$\begin{array}{l}\text { Tube Sheet } \\
\text { SA 266 Cl 2 }\end{array}$ & 194173 & 482.3 & 250 & 217.5 & 144.7 & 217.12 & 167.5 \\
\hline $\begin{array}{l}\text { Tubes } \\
\text { SA 334 Gr 1 }\end{array}$ & 194173 & 379 & 205 & 181.5 & 120.6 & 181 & 167.5 \\
\hline
\end{tabular}

a

\section{Calculation temperatures are:}

Fluid design temperature for shell material channel side.

Fluid design temperature for shell material shell side.

Average design temperature of shell and tube sides for tube sheet and tubes.

b Channel side, SA $537 \mathrm{CL}-2$ ( $t \leq 63.5 \mathrm{~mm}$ ). Table $\mathrm{Y}-1$, Sec. II, Part $\mathrm{D}$ does not directly provide $\mathrm{R}_{\mathrm{p}}, 0.2 / \mathrm{t}_{\text {calc }}$ at $190^{\circ} \mathrm{C}$. Interpolation between adjacent values gives smaller yield in comparison to $1.5 \mathrm{~S}_{\mathrm{m}}$. The $1.5 \mathrm{~S}_{\mathrm{m}}$ has been selected. 
In the present FE model, the standard tube sheet thickness of $135 \mathrm{~mm}$ calculated according to the classical ASME method and shown in Figure 4 is reduced to $100 \mathrm{~mm}$. The FEA model, which was created using the commercial finite element code ANSYS [14], is illustrated in Figure 5 and is similar to that used in reference [5]. To minimise computing requirements, a symmetrical segment of vessel is modelled. The tube sheet, shell and head are modelled using 3D isoparametric solid elements. The tubes to tubesheet attachments are of the welded type, i.e. they are connected through common nodes. The tubesheet to shell junctions have a groove with $12.5 \mathrm{~mm}$ radius, which has been modelled with an adequate number of elements.

In small deformation analysis, ANSYS "Solid 45" 8 node, 3D solid isoparametric brick elements were used [14, ANSYS element manual] . In large deformation analysis, ANSYS "Solid 185" 20 node, 3D solid brick elements were used. The Solid 185 element is a higher order version of solid 45 which allows uniformly reduced integration and enhanced large strain capability, as it is formulated to capture higher order strain terms. However, these elements must be used with care as volume and shear locking may be encountered.

The locking mechanism at elements level can result in solution divergence. The outer four rows of tubes are also modelled using these 3D solid elements, as shown in Figures $5 \mathrm{a}$ and $5 \mathrm{~b}$. The structural effect of the remaining tubes is modelled using 12 link elements for each hole in the tube sheet with total axial stiffness equivalent to that of a single tube. The multilinear and non linear kinematic hardening options are not appropriate for the link elements in large strain analysis. For large deformation analysis, these elements were replaced by simple supports applied to the tube sheet locations. In all, the model consists of 42,482 elements and 82,238 nodes. Symmetry boundary conditions are applied on the cut surfaces of the modelled segment, as shown in Figure $5 \mathrm{~d}$. Pressure loading is applied to the tube sheet, including the internal pressure in the tubes themselves, as illustrated in Figure $5 \mathrm{e}$.

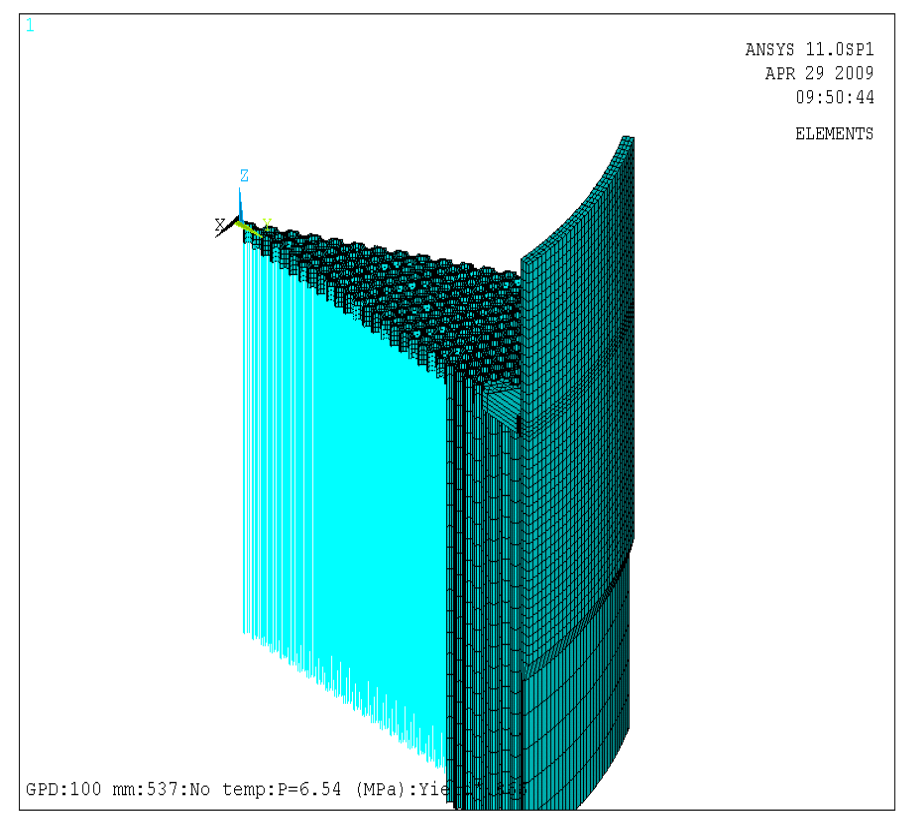

Figure 5a. Finite element model. 


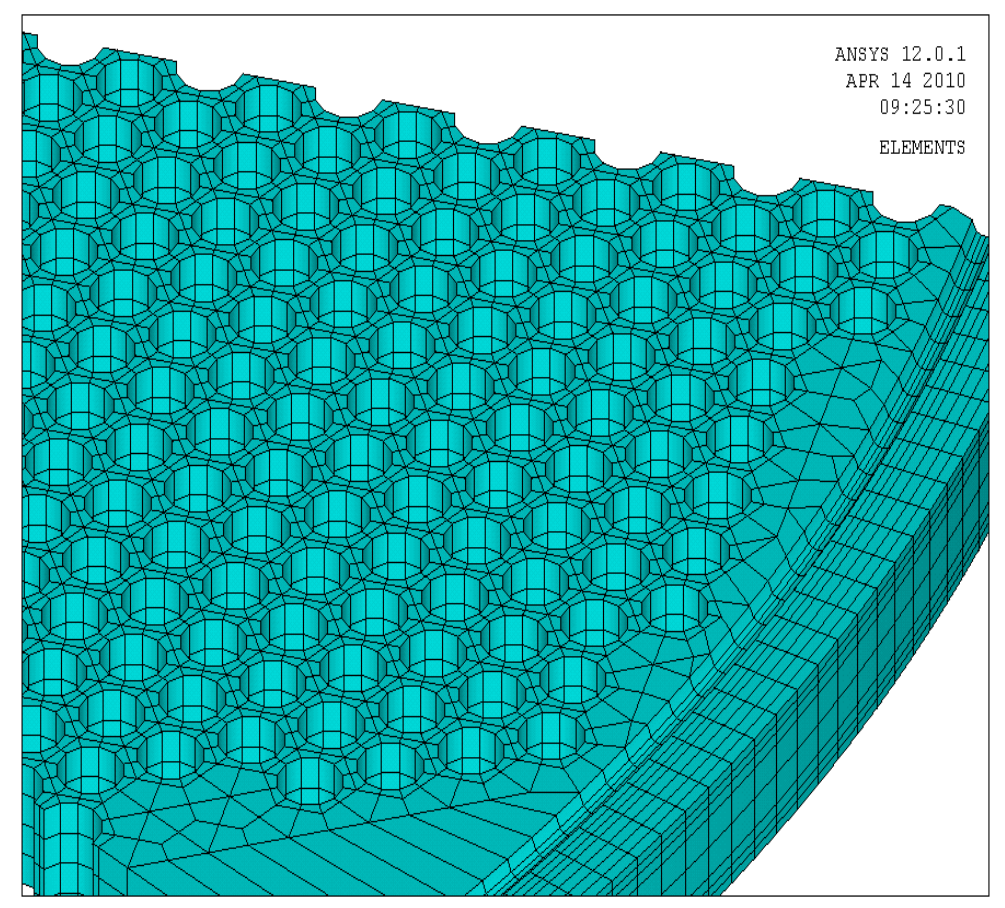

Figure 5b, Perforated Tubesheet.

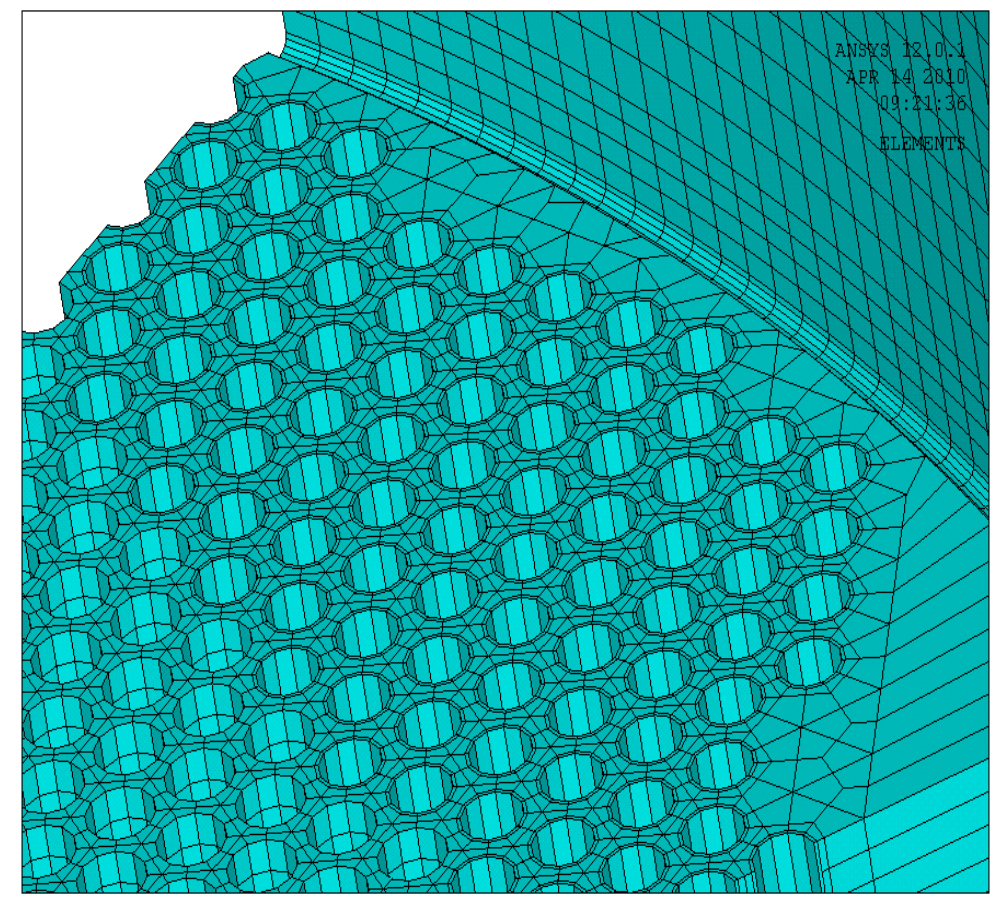

Figure $5 c$, Radius location at the junction of tube sheet and shell. 


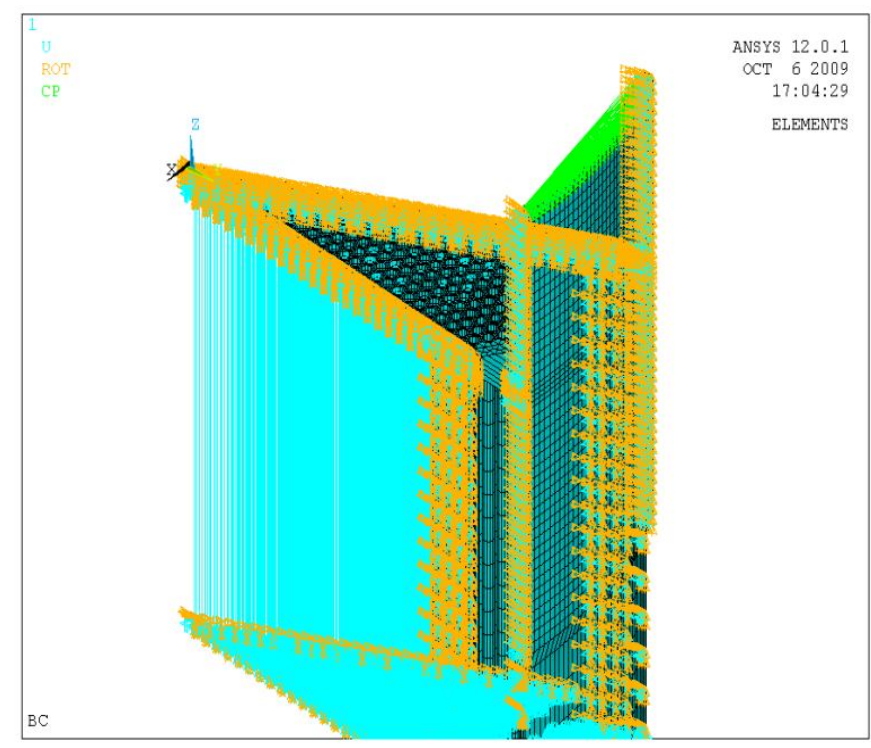

Figure 5d, Displacements Boundary Condition.

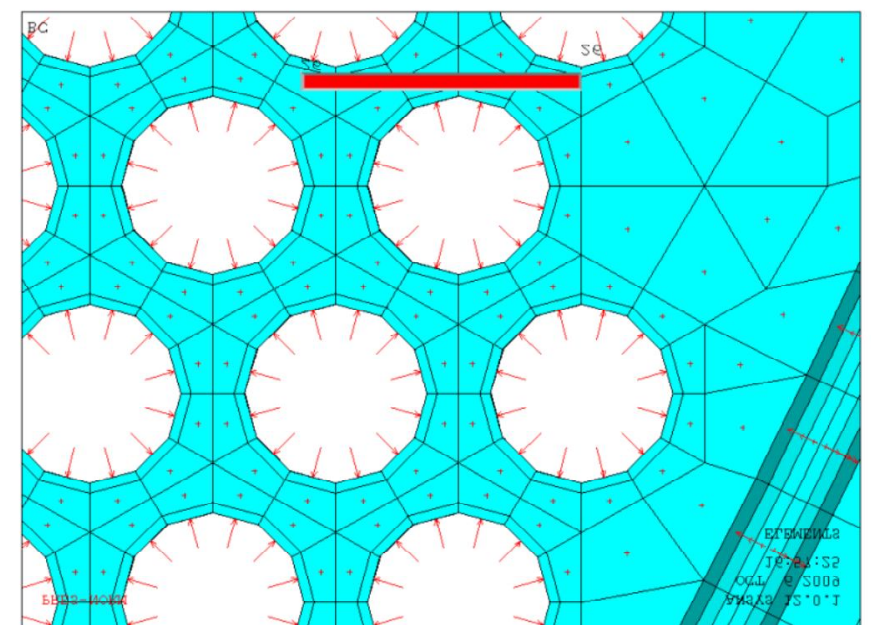

Figure 5e, Pressure Loading.

\section{Material Models}

This specific exchanger and nearly all other similar types are operated in base-load mode, with little or no fluctuation on the design pressure and design temperature except for full shutdowns. Based on the exchanger operating mode and in the absence of cyclic loads, the hardening parameters are bounded with classical formulation available within ANSYS [14]. Bilinear isotropic, multilinear isotropic, bilinear kinematic and multilinear kinematic rules have been used on the present investigation. Bilinear isotropic work hardening is based on the assumption of isotopic work hardening, with one straight line representing the elastic behaviour and a second straight line representing the post-yield behaviour. M ultilinear isotopic work hardening fits a multilinear approximation to the elastic-plastic stress strain curve. Linear kinematic hardening uses the Prager [12] rule with a simple representation of the linear dependency between yield surface movement and increments of plastic strain. The multilinear hardening parameter is formulated according to the Besseling [13] model, also termed a sub- layer model, and the material response is represented by multiple layers of perfectly plastic material; the total response is obtained by the weighted average behaviour of all layers. Individual weights are derived from the uniaxial stress- strain curve. The above material models are termed coupled types as the plastic modulus calculation is coupled with hardening rule through a consistency condition. 
In the bilinear hardening analyses, a post-yield tangent modulus of $10 \%$ of the elastic modulus has been assumed. 10\% strain hardening has previously been used in references [6], [7], [8]. The principal structural strain in these analyses is limited to $5 \%$ throughout: if the solution continues to converge at the corresponding load level the solution is terminated when $5 \%$ strain is reached. The multilinear hardening curves used were derived from the true stress-strain curve procedure outlined in Annex 3.D of ASM E [2].

\section{Small Deformation Analysis Results}

Figure 6 shows the limit state von Mises equivalent plastic strain distributions in the tube sheet as calculated by small deflection, elastic-perfectly plastic isotropic analysis.

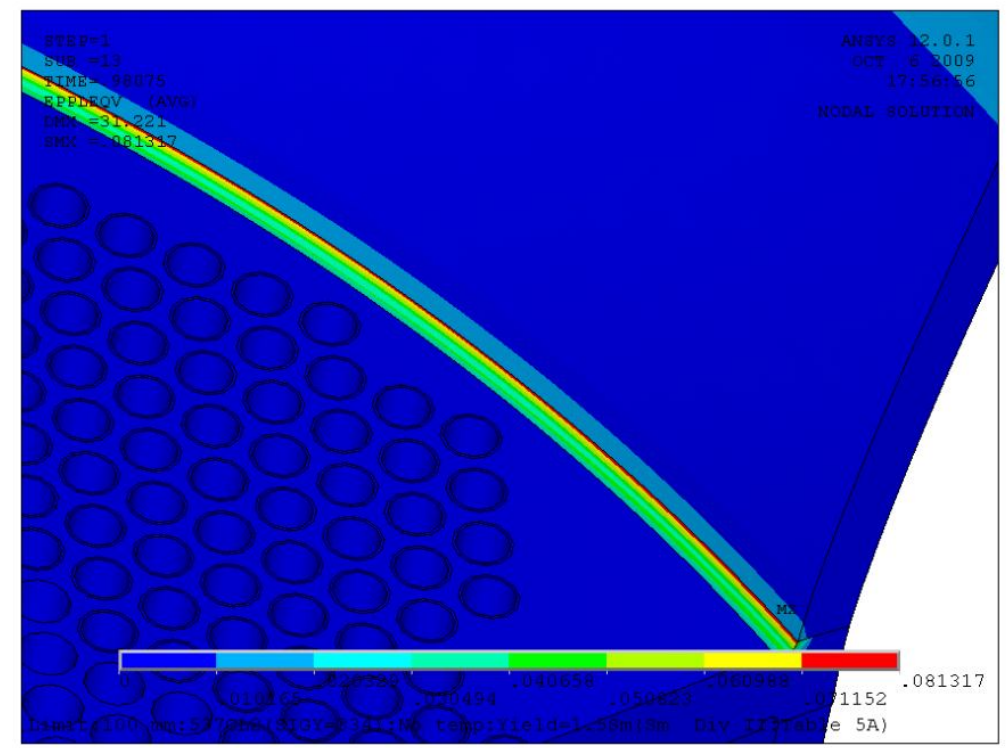

Figure 6. Von M ises equivalent plastic strain at the limit load: $\left[\varepsilon_{\mathrm{pl}}\right]_{\max }=.0813$

Figure 7 shows the von $M$ ises equivalent plastic strain distributions at the same (limit) load as calculated by small deflection, bilinear (10\%) isotropic hardening analysis.

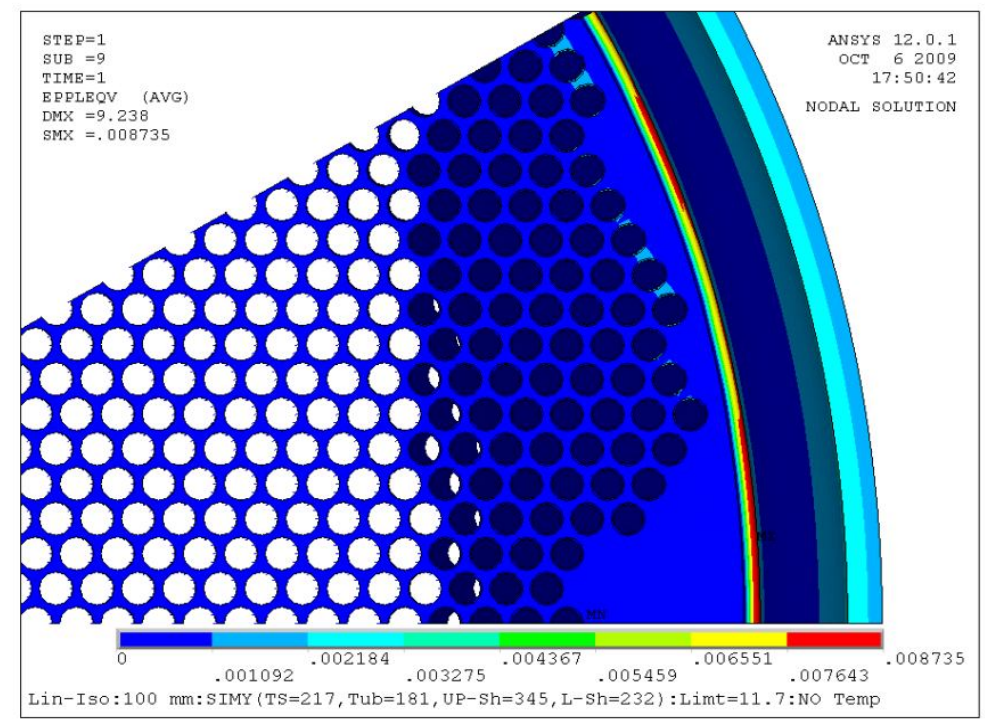

Figure 7. Von Mises equivalent plastic strains, small deflection, bilinear Isotropic Hardening: $\left[\varepsilon_{\mathrm{pl}}\right]_{\max }=.0087$ 
Figure 8 shows the von M ises equivalent plastic strain distributions at the same (limit) load as calculated by small deflection, multilinear isotropic hardening analysis.

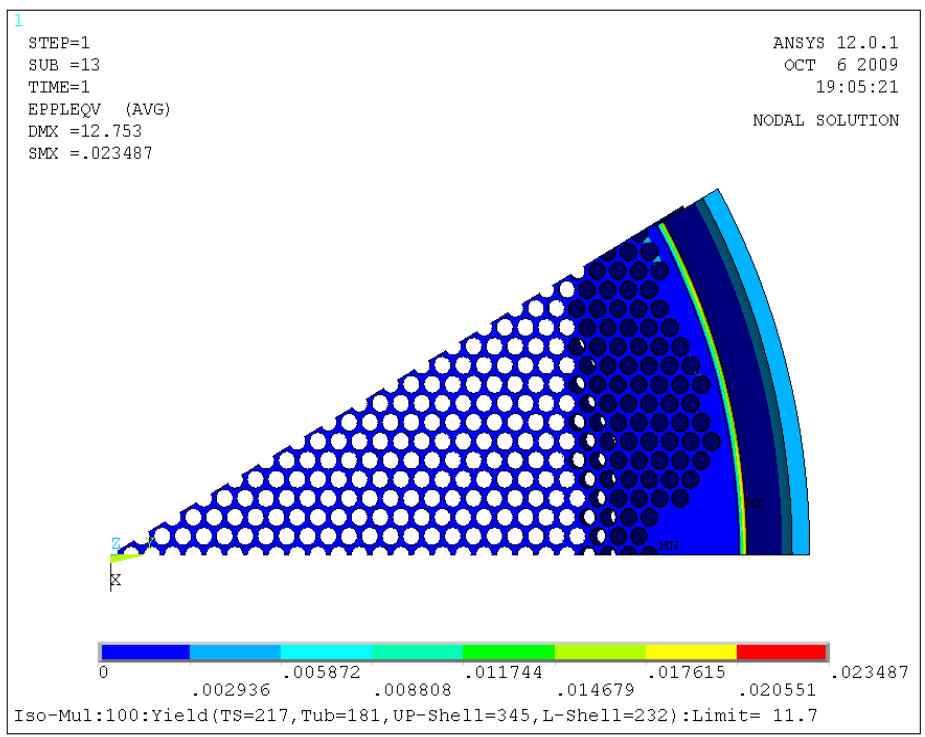

Figure 8, Von Mises equivalent plastic strains: small deflection, multilinear Isotropic Hardening: $\left[\varepsilon_{\mathrm{pl}}\right]_{\max }=$ .0234 .

Figures 6 to 8 show that the highest plastic deformation occurs in the region of the groove between the tube sheet plate and the shell of the vessel.

Table 2 summarises the calculated limit load, the ASME III plastic loads evaluated using the TES criterion, the load as $5 \%$ von M ises plastic strain and the numerical instability load given by the models considered. The deformation parameter used in the TES construction was displacement of one of the nodes in the highly loaded groove region of the tube sheet. It is noted that limit load reported in the reference [5] is different from the value given in Table 2. This is because the reference [5] value was factored in accordance with the procedure specified in reference [4], which requires a limit load based on the Tresca yield criterion. 
Table 2: Plastic Load (M Pa): Small Deformation

\begin{tabular}{|l|l|l|l|l|}
\hline \multirow{4}{*}{ Procedure } & \multicolumn{2}{|l|}{ Isotropic } & \multicolumn{2}{l|}{ Kinematic } \\
\cline { 2 - 6 } & Bilin. & $\begin{array}{l}\text { Multi- } \\
\text { Lin. }\end{array}$ & Bilin. & $\begin{array}{l}\text { Multi- } \\
\text { Lin. }\end{array}$ \\
\cline { 2 - 6 } & $\begin{array}{l}\mathrm{E}_{\mathrm{t}}= \\
0.1 \mathrm{E}\end{array}$ & $\begin{array}{l}\text { True } \\
\text { stress- } \\
\text { strain }\end{array}$ & $\begin{array}{l}\mathrm{E}_{\mathrm{t}}= \\
0.1 \mathrm{E}\end{array}$ & $\begin{array}{l}\text { True stress } \\
\text { strain }\end{array}$ \\
\hline Limit Load & 11.7 & 11.7 & 11.7 & 11.7 \\
\hline TES & 22 & 16.4 & 21.9 & 15.7 \\
\hline $\begin{array}{l}\text { Load producing 5\% } \\
\text { Mises plastic Strain. }\end{array}$ & 21 & 13.3 & 24 & 12.99 \\
\hline Numerical Instability & - & 21 & - & 21 \\
\hline
\end{tabular}

Table 2 shows that the TES plastic load is significantly greater than the limit load for all the strain hardening cases considered. Fixed tube sheet exchangers are essentially very stiff in nature and the tube sheet tends to move as a rigid body except at its edge, where deformation is dictated by a combined action of channel side shell, outer tubes bending and tubesheet edge movements. The magnitudes of the displacements under various loads are small; for example, Figure 9 shows the displacement plot of the tube sheet subject to 22 $\mathrm{MPa}$ pressure in the bilinear isotropic analysis.

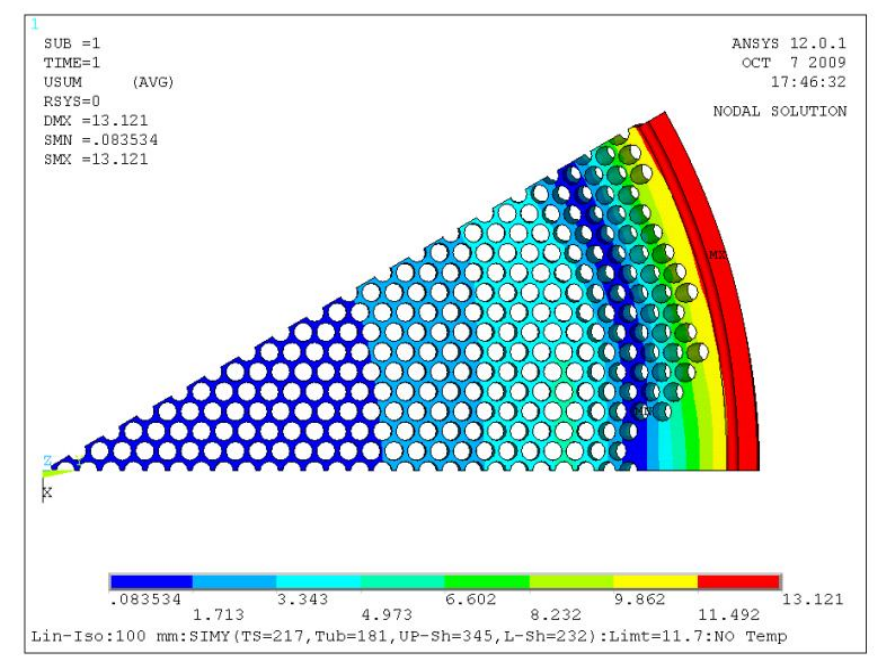

Figure 9. Small Deformation: Load-Deformation: $P=P_{\text {TwS }}=22$ : Bilinear Isotropic: $E_{t}=0.1 \mathrm{E}: \delta_{\text {sum }}=13.12 \mathrm{~mm}$ 
In a study of perforated plates, O'Donnel [10] reported problems related to obtaining the intersection of twice elastic slope line with load- deformation plot. In the present investigation, the twice elastic slope lines intersected the load deformation plots for all various material models; however, due to the sharp gradient of the plastic region of the load-deformation diagram the intersection occurs at a high load level compared to the limit load. Figure 10 shows the TES construction for the bilinear isotropic analysis.

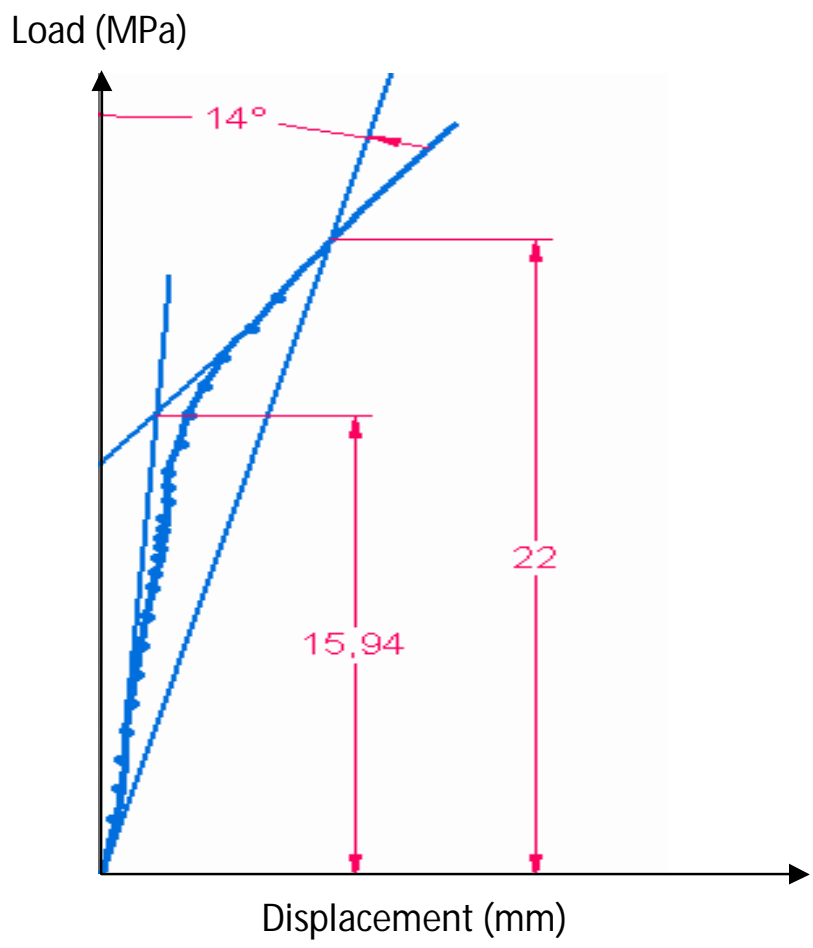

Figure 10. Small Deformation: Load-Deformation, $\mathrm{P}_{\mathrm{TWS}}=22, \mathrm{P}_{\mathrm{Tl}}=15.9$ : Linear Isotropic: $\mathrm{E}_{\mathrm{t}}=0.1 \mathrm{E}$

Table 2 also shows that the ASM E VIII Division 2 Global Criterion plastic load, the numerical instability load of the model, is also significantly greater than the limit load of the structure. Analysis based on a bilinear hardening material model will continue to exhibit converge at very high loads, as the post-yield material model does not limit plastic strain allowing internal stress distributions to equilibrate with the applied load even at excessive load levels. In the analyses reported here, a 15\% strain limit was applied to terminate the analysis when this value was reached. In the multilinear hardening analyses, equilibrium was violated when the applied pressure exceeded $21 \mathrm{MPa}$.

The results given in Table 2 indicate that the loads calculated by TES method (with the possible exception of the linear kinematic analysis) are not suitable as the basis of design loads due to the excessively high plastic strain in the component. 
The plastic loads based on plastic work curvature criteria and tangent intersection methods are given in Table 3. Figure 11 shows the PWC plot for bilinear isotropic analysis which shows a graph of load versus plastic work and a graph of curvature versus plastic work plotted on the same diagram.

Table 3: Plastic Load (M Pa): Small Deformation

\begin{tabular}{|l|l|l|l|l|}
\hline \multirow{2}{*}{} & \multicolumn{2}{|l|}{ Isotropic } & \multicolumn{2}{l|}{ Kinematic } \\
\cline { 2 - 5 } Procedure & Bilin. & Multi- & Biin. & M ulti- \\
& $\begin{array}{l}\mathrm{E}_{\mathrm{t}}= \\
0.1 \mathrm{E}\end{array}$ & $\begin{array}{l}\text { True } \\
\text { stress- } \\
\text { strain }\end{array}$ & $\begin{array}{l}\mathrm{E}_{\mathrm{t}}= \\
0.1 \mathrm{E}\end{array}$ & $\begin{array}{l}\text { True } \\
\text { stress- } \\
\text { strain }\end{array}$ \\
\hline $\begin{array}{l}\text { Max. Curv. } \\
\text { of plastic work. }\end{array}$ & 12.8 & 14.3 & 12.7 & 14.2 \\
\hline $\begin{array}{l}10 \% \text { of max. } \\
\text { curvature }\end{array}$ & 15 & 17.6 & 17 & 18.2 \\
\hline TI & 15.9 & 16.5 & 16.9 & 15.4 \\
\hline
\end{tabular}

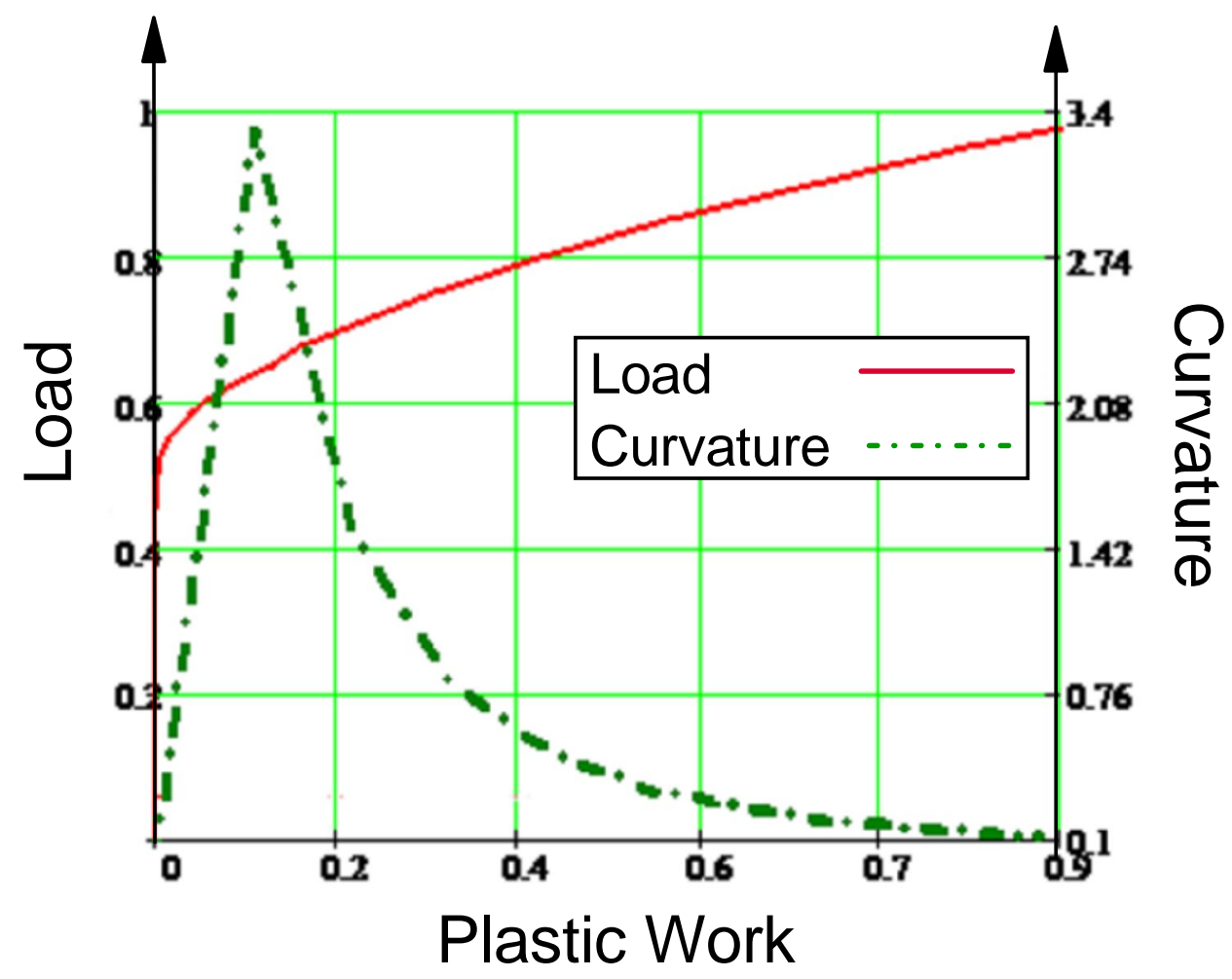

Figure 11. Small Deformation: PWC plot for Bilinear Isotropic: $\mathrm{E}_{\mathrm{t}}=0.1 \mathrm{E}: \mathrm{P}_{\text {plast }}=12.8 \mathrm{MPa}$ 
The PWC and TI criterion loads given in Table 3 indicate a consistent representation of the effect of work hardening on the load carrying capacity of the structure. The deformation parameter used in the $\mathrm{TI}$ construction was the same nodal displacement as used in the TES criterion. The PWC criterion does not require of a local deformation parameter of this type, as it is based on the total plastic work done on the structure.

The loads corresponding to maximum plastic work curvature are greater than those obtained by limit analysis but are conservative in that the maximum curvature occurs during stress redistribution prior to the onset of gross plastic deformation. The $10 \%$ of maximum curvature value is indicative of the load level at which gross plastic deformation occurs. The TI plastic loads given in Table 3 are greater than the equivalent maximum PWC loads, however it is noted that these loads are dependent on interpretation of where the tangent to the plastic region of the load deformation curve (for example, Figure 10) should be drawn. This is a subjective decision that can significantly affect the calculated of the plastic load.

\section{Large Deformation Analysis Results}

A modified version of the Voce [16] equation is given in reference [14] for non linear isotropic calculations associated with large strain analysis. Here, modified Voce coefficients [14] were calculated through a third order polynomial obtained based on the reference [6] true stress-strain data. The total plastic work was calculated separately through Reference [14] sets of coefficients. As the Voce equation is in the form of an exponential function, this was done by writing out the first 5 components of Taylor series for each related term. Three individual sets of the coefficients produced in this way were checked and it was noted that they produce the same level of plastic work for each load step. Writing out additional terms can improve the result somewhat.

Large deformation theory plastic loads based on the PWC criterion are compared with the numerical instability load of the vessel in Table 4.

Table (4): Plastic Load (MPa): Large Deformation

\begin{tabular}{|l|l|l|l|l|l|}
\hline \multirow{4}{*}{ Procedure } & \multicolumn{2}{|l|}{ Isotropic } & \multicolumn{2}{l|}{ Kinematic } \\
\cline { 2 - 6 } & Bilin. & $\begin{array}{l}\text { Multi- } \\
\text { Lin. }\end{array}$ & Voce & Bilin. & $\begin{array}{l}\text { Multi- } \\
\text { Lin. }\end{array}$ \\
\cline { 2 - 6 } & $\begin{array}{l}\mathrm{E}_{\mathrm{t}}= \\
0.1 \mathrm{E}\end{array}$ & $\begin{array}{l}\text { True } \\
\text { stress- } \\
\text { strain }\end{array}$ & $\begin{array}{l}\text { Exp. } \\
\text { Law }\end{array}$ & $\begin{array}{l}\mathrm{E}_{\mathrm{t}}= \\
0.1 \mathrm{E}\end{array}$ & $\begin{array}{l}\text { True } \\
\text { stress } \\
\text { strain }\end{array}$ \\
\hline $\begin{array}{l}\text { Max. Curv. } \\
\text { of plastic work. }\end{array}$ & 13.12 & 13.7 & 12.92 & 14.5 & 12.8 \\
\hline $\begin{array}{l}10 \% \text { of max. } \\
\text { curvature }\end{array}$ & 17.4 & 17.1 & 15.01 & 20 & 21.6 \\
\hline Instab. Load & 12.4 & 12.4 & 12.4 & 12.4 & 12.4 \\
\hline Numerical Instability & 24 & 21 & 19 & 29 & 25 \\
\hline
\end{tabular}




\section{Discussion of results}

The different types of analysis and different plastic load criteria considered in the investigation resulted in a wide range of calculated plastic pressures. These ranged from limit pressure of $11.7 \mathrm{MPa}$ to numerical instability pressures in excess of twice this value. In the case of the small deformation bilinear hardening analysis, numerical instability did not occur for the load range considered and the analysis was terminated when the plastic strain exceeded $15 \%$.

It is noted that for a monotonically increasing proportional load (i.e. pressure), the results of plasticity calculations using similar bilinear or multilinear isotopic and kinematic hardening material models should theoretically be the same. Table 2 shows that this is the case for the limit analyses presented but in the case of the strain hardening analyses, Tables 2 to 4 show some differences in the post-yield stress strain curves, due to the slightly different kinematic and isotropic hardening plasticity formulations adopted in ANSYS [14]. This in turn resulted in evaluation of different plastic loads for isotropic and kinematic analysis when the plastic load criteria were applied to the stress strain curves in some cases.

The TES and TI plastic pressures require specification of a deformation parameter to define a characteristic load-deformation curve. In the analyses presented here, the displacement of a highly loaded node in the groove between the tube sheet and shell was used as the deformation parameter. This parameter resulted in high values of TES plastic load due to the stiff nature of the tube sheet and constrained nature of the plastic zone. The TES criterion does not realistically capture the nature of the plastic collapse mechanism in this situation and is not therefore suitable as the basis for design against gross plastic deformation. The $\mathrm{TI}$ criterion is dependent on where the tangent is drawn to the plastic deformation portion of the loaddeformation curve. In this configuration, the curve exhibits a steady slope at high load levels and taking the tangent from this region results in relatively high values of TI plastic load. However, extensive plastic deformation occurs in the grooved region at the edge of the tube sheet at significantly lower pressures and it is possible that a gross plastic deformation mechanism forms in the structure prior to the steady state plasticity exhibited at higher pressures.

The ASME VIII Div 2 Global Criterion of structural instability indicated by convergence failure is not appropriate for the small deformation bilinear analyses presented (as the Code requires use of large deformation theory). These models continue to converge at very high load levels and solution is terminated by defining a limiting strain for the FE solver. In the large deformation analyses, numerical instability occurs at high load levels, in excess of twice the limit load. In these cases a Service Criterion must be applied in order to define a plastic load suitable for design. Direct usage of plastic collapse load is not appropriate as at this higher load the deformations and strains are very high. High level of deformation could cause weld distortion at the junction of tubes to tube sheet, or can create movements of the tubes that are limited by presence of the baffles. The PWC criterion is an appropriate Service Criterion with respect to preventing excessive plastic deformation.

The PWC maximum curvature indicates that considerable stress redistribution has occurred in the structure but the state corresponding to gross plastic deformation in limit analysis has not yet been achieved. At higher loads, the amount of stress redistribution decreases and a gross plastic deformation mechanism is established. It has previously been suggested that reduction in curvature to $10 \%$ of the maximum is a suitable indication of gross plastic deformation. It is proposed here that the maximum PWC is a suitable indicator of the plastic pressure of the vessel. This is a conservative interpretation but results in a plastic load for design purposes that is greater than the limit load due to the effect of work hardening on the development of a plastic failure mechanism.

For the present FEA model, data sheet thickness of $136 \mathrm{~mm}$ reported according to the classical ASME method has been reduced to $100 \mathrm{~mm}$ for purpose of the plastic load calculation. It has been shown that the $100 \mathrm{~mm}$ thickness can withstand the pressure of $12.8 \mathrm{M} \mathrm{Pa}$ (from large deformation analysis) according to true stress strain material data. This pressure is almost 3 times higher than the datasheet design pressure 
meaning that the thickness can be further reduced using this method, however usage safety factors must be considered.

One additional observation is noted here: as tubesheet is supported by numerous tubes the effect of the tubing is to prevent excessive relative transverse deformation of different sections of the tubesheet. In effect making these sections relatively rigid. However the sections of the tubesheet without tubes and the sections of the tubesheet located at the outer tubes rows do experience bending. The magnitude of the plastic load therefore will have a high dependency on the behaviour of these critical regions.

\section{Conclusions}

Plastic load calculated according to the curvature criteria is not dependent on the local parameters as it is based on the total plastic work done on the structure. In comparison with other methods the procedure is unique and has been successfully applied to very complex tube sheet geometry. Adoption of the method for design purpose after applying usage safety factor is recommended.

\section{Acknowledgement}

Partial support of Foster Wheeler Energy Limited (Reading Office) on preparation of this work is acknowledged. 
References:

[1] ASM E, Boiler and Pressure Vessel Code, Sec. VIII, Div. 1, American Society for Mechanical Engineers, New York, 2007.

[2] ASM E, Boiler and Pressure Vessel Code Section VIII, Div. 2, American Society for Mechanical Engineers, New York, 2007.

[3] ASM E, Boiler and Pressure Vessel Code Section III, American Society for Mechanical Engineers, New York, 2007.

[4] EN 13445-3,"European Standard for Unfired Pressure Vessels- Part 3: Design", European committee for Standardization (CEN)., 2002.

[5] Behseta,K., Schindler,S., 2006," On the Design of the Tube Sheet and Tube sheet- toShell Junction of a Fixed Tube Sheet Exchangers", International Journal of Pressure Vessel and Piping, Vol. 83, number 10, PP 714-720.

[6] Muscat, M., M acKenzie, D., Hamilton, R., 2003, "A Work Criterion for Plastic Collapse", International Journal of Pressure Vessels and Piping, Vol. 80, PP 49-58.

[7] Camilleri, D., M acKenzie, D., Hamilton, R., 2008, “Evaluation of Plastic Loads in Torispherical Heads Using a New Criterion of Collapse", ASME J ournal of Pressure Vessel Technology, Vol.130, PP 011202-1 to 011202-8.

[8] Kalnins, A., Rana, M .D., 1996," A New Design Criterion Based on Pressure Testing of Torispherical Heads", WRC Bulletin 414, PP 1-60.

[9] Li. Hongjun, M acKenzie, D., 2005," Characterising Gross Plastic Deformation in Design by Analysis", International Journal of Pressure Vessel and Piping, Volume 82, PP 777- 786.

[10] Gerdeen,J.C.,1979," A Critical Evaluation of Plastic Behaviour Data and a United Definition of Plastic for Pressure Components", WRC Bulletin 254, PP 1-89.

[11] Save, M., Experimental verification of plastic limit analysis of torispherical and toriconical heads. Pressure vessel piping: design and analysis, vol. 1. New York: ASM E; 1972. P. 382-416.

[12] Proger, W., 1956. A new method of analyzing stresses and strains in work hardening plastic solids. Journal of Applied Mechanics 23, 493-496.

[13] Besseling, J.F., 1958. A theory of elastic, plastic and creep deformation of an initially isotropic material. Journal of Applied Mechanics 25, 529,536

[14] ANSYS Computer Program, Ver. 12.

[15] ASM E, Boiler and Pressure Vessel Code Sec II, Part D, American Society for Mechanical Engineers, New York, 2007.

[16] Voce, E, 1955," A Practical Strain- Hardening Function", Metallurgia. 
